\title{
Understanding Visitors' Responses to Intelligent Transportation System in a Tourist City with a Mixed Ranked Logit Model
}

\author{
Yang Liu, Jing Shi, and Meiying Jian \\ Department of Civil Engineering, Tsinghua University, Beijing 100084, China \\ Correspondence should be addressed to Jing Shi; jingshi@tsinghua.edu.cn
}

Received 10 November 2016; Revised 22 January 2017; Accepted 6 February 2017; Published 22 February 2017

Academic Editor: Zhi-Chun Li

Copyright (C) 2017 Yang Liu et al. This is an open access article distributed under the Creative Commons Attribution License, which permits unrestricted use, distribution, and reproduction in any medium, provided the original work is properly cited.

\begin{abstract}
One important function of Intelligent Transportation System (ITS) applied in tourist cities is to improve visitors' mobility by releasing real-time transportation information and then shifting tourists from individual vehicles to intelligent public transit. The objective of this research is to quantify visitors' psychological and behavioral responses to tourism-related ITS. Designed with a Mixed Ranked Logit Model (MRLM) with random coefficients that was capable of evaluating potential effects from information uncertainty and other relevant factors on tourists' transport choices, an on-site and a subsequent web-based stated preference survey were conducted in a representative tourist city (Chengde, China). Simulated maximum-likelihood procedure was used to estimate random coefficients. Results indicate that tourists generally perceive longer travel time and longer wait time if real-time information is not available. ITS information is able to reduce tourists' perceived uncertainty and stimulating transport modal shifts. This novel MRLM contributes a new derivation model to logit model family and for the first time proposes an applicable methodology to assess useful features of ITS for tourists.
\end{abstract}

\section{Introduction}

Tourist cities in China have witnessed an impressive growth in tourism industry over the last decade. In particular, this growth should considerably owe to the surge of the "Free Independent Tourists" (FIT), a widely used terminology referring to an individual or a small group who travel and vacation with a self-booked and deeply customized itinerary. Unlike traditional guided tourists, FIT can choose the transport to destination and local transport by themselves with the help of various tourism information and/or tips from open information sources (e.g., websites). Many of them prefer to drive individual vehicles (IV) when traveling. In this research, they are called FIT who travel by individual vehicles (FIT by IV). FIT by IV include both the drivers and accompanying tourists in private cars or rental cars that are not changed during their whole journey. Alongside the FIT by IV, other FITs may use noncar modes (like plane, train, and coach) to arrive at their tourism destinations and do not rent a car there. Instead, they would prefer to depend on local public transport services. Thus, these FIT without personal or rental cars are herein distinguished as Free Independent Tourists who travel by public transport (FIT by PT). The developments of FIT by IV and FIT by PT have both flourished China's tourism industry.

Coinciding with substantial economic benefits from the influx of tourists, traffic congestion and environmental pressure have posed serious threat to popular tourist destinations at the same time, which would adversely affect the sustainability of tourism. Traditional solutions, such as building more infrastructures to meet the growing number of FIT by IV, cannot fundamentally mitigate those problems and may even deteriorate the situation as the personal vehicle use may be stimulated. Another solution is to improve public transport services and shift more tourists from personal cars to green public transport modes to alleviate roadway congestion and reduce vehicle emissions [1-3]. The latter provides more smart and feasible strategies that could enhance the transport system in an efficient and ecofriendly way without weakening the mobility of tourists.

However, according to the report issued by Tourism Research Center of Chinese Academy of Social Sciences, in the year of 2015, approximately $58.5 \%$ of the total Chinese domestic tourists arrived in tourism destinations by car 
[4]. Meanwhile, China National Tourism Administration revealed that about $75 \%$ of the total domestic tourists were FIT in the same year [5]. These two data indicate a high proportion of FIT by IV and a relatively low ridership of public transit among FIT in China. The possible reasons are the following: (1) FIT by IV in China may regard a driving tour as a new fashion with comfort and convenience; (2) tourist city may lack adequate public transport services for visitors; (3) unlike daily commutes, travel routes in a tourist city are often irregular; thus tourists may find difficulties using public transit in an unfamiliar city if local transportation information is limited. For example, when traveling for tourism activities, 36\% of the visitors in the city of Changchun would take buses, while this ratio among local residents was $61 \%$ [6]. With empirical evidence from four tourism attractions in Germany, Gronau and Kagermeier [7] identified several key factors for successful leisure and tourism public transport, including transparency and quality of the public transport service, restricting use of private car, and market promotion strategies (e.g., combined tickets for both tourism attraction and public transport). In particular, the first factor regarding "transparency" was in line with the dimension of simplicity proposed by Frima et al. [8] and "ease of use" which was identified by Schiefelbusch et al. [9]. From this enlightening perspective, more information on public transport services, especially in the context of tourism, should be offered to improve public awareness and acceptance. Kenyon and Lyons [10] also suggested that presentation of integrated multimodal traveler information for a journey in response to a single enquiry could influence drivers' perceived utility of noncar modes, which can contribute to a modal shift with overcoming the underlying habitual and psychological barriers.

With widespread adoption of varied sensors, or the concept of "Internet of Things", large-scale transport data can be collected by Intelligent Transport System (ITS) to analyze the operation state of a transport system. Meanwhile, information and communication technologies are accelerating the development of ITS applications. From early real-time arrival screens at transit stops to recent apps in mobile devices that release transit information [11], ITS tools are capable of delivering integrated multimodal traveler information to tourists in more cost-effective and user-friendly ways. Therefore, as a potential approach, ITS enables the integration of travel services (e.g., intelligent buses, public bicycles) and information services (e.g., traffic condition, parking fee, and waiting time for public transit), which can better balance travel demands generated from tourists and transport supply from tourist cities.

Previous studies have rarely investigated the impacts of ITS on tourism transport users, while urban commuters' responses to real-time transport information have been extensively observed and analyzed. Transit information users are observed to have a number of important responses, including shortenings in both perceived and actual waiting time with the help of detailed arrival information [1215], increased satisfaction with transit services [16-18], and increased ridership and transfers [15, 17-19]. Long-period observation and corresponding regression analysis can help to investigate the change in commuters' ridership with influence from various factors, and then most of these findings were obtained from longitudinal data $[16,19,20]$. However, adopting this method in the study of tourists seems to make little sense. Different from daily commutes, visitors' routes in a tourist city are not frequently repeated. As a result, setting up a control group without instant access to transit information to explore the benefits of ITS applications in a natural experiment could be hard to implement. Moreover, several studies found no significant changes in commuters' ridership with the introduction of transit information [20] or merely "modest" [19], because daily commute trips are relatively fixed and inelastic. Therefore, different levels of familiarity with the local transport system and different travel patterns between tourists and commuters should be noted. A novel methodology is required when probing into the impacts of ITS applications on tourists.

To go beyond the limitations of longitudinal data, stated preference (SP) survey is employed in this research to collect tourists' potential choices on transportation mode by imitating possible scenarios that they may face in the future. As a growing number of tourists currently inquire transportation information via mobile devices [11] and this trend seems to expand, SP survey is designed for tourists to complete it on mobile devices to cater to their habits in tourism information inquiry. SP survey that is conducted on mobile devices can help to record the responses of these potential ITS information users. At the same time, data is collected in a more efficient way especially compared to traditional paper-based questionnaire. Correspondingly, with the data from mobile devices, a novel Mixed Ranked Logit Model (MRLM) will be gradually developed to estimate how ITSsupported travel services influence transport modes choices of the tourists who are accessible to ITS information, which is the objective of this research. The rest of this paper is organized as follows. In Section 2, the formulation of MRLM is introduced and the reason for developing such a model in this study is explained. After that, in Section 3 of a case study, data collecting strategy and the sample characteristics are described. Then estimation results of MRLM are presented in Section 4 with adoption of simulation-based estimation procedure. In Section 5, potential changes brought by ITS on tourism-related transportation mode choices are predicted. Finally, the main conclusions are highlighted in the last section with some suggested directions for future research.

\section{Methodology}

SP survey is a widely used methodology in analyses of travel choices. Commonly, three responses are designed in SP surveys: (1) the single most-preferred alternative, (2) ranking of alternatives, and (3) rating of alternatives [21]. Among all these dimensions of response, single choice causes the least burden on respondents, but has the least preference information and consequently requires a relatively larger sample size. Rating of alternatives, on the contrary, is the most demanding to respondents, but provides the richest preference data. However, the ranking of alternatives asks respondents to decide the whole or partial preferred order 
from the option set, then it can generate more data than just a single choice. Meanwhile, despite getting less information than quantitative evaluations of preference in the rating approach, the ranking of alternatives can help to avoid heavy burden imposed on respondents, and controls the possible influences on response reliability that may be caused by respondents' impatience. Therefore, the ranking method will be employed in this study as it can balance the sample size and data quality in SP surveys compared to other two methods.

Beggs et al. [22] and Chapman and Staelin [23] first applied the ranked data in several logit model formulations. They exploited the information of ranked data with an "explosion procedure" of the entire ranking. The entire ranking of a set of $J$ alternatives can be "exploded" into a sequence of $J-1$ independent choosing steps. The first choosing step is to select the perceived best alternative from all the $J$ available alternatives. The second step is to select the second-best one from the remaining $J-1$ alternatives excluding the chosen one in the preceding step, and so on until the $(J-1)$ th step in which an alternative is to be assigned rank $J-1$ from the last two remaining alternatives that have not been ranked before. Although ranking of all the available alternatives can provide much preference information, Hausman and Ruud [24] argued that respondents might give less consideration to decide lower ranks compared to higher ranks as the variance in the ranking of less preferred alternatives increased. In order to reduce the negative effects of lower ranks, this paper focuses on the ranking of best two alternatives that most respondents pay attention to [25], and at the same time respondents will not find much difficulty in ranking. It should be noted that early logit models for analyzing ranked data were mostly derived from standard multinomial logit model (MNL) [22, 23]. However, standard MNL exhibits independence from irrelevant alternatives (IIA), which implies proportional substitution across alternatives. Moreover, the assumption that each choosing step in different ranking level was an independent observation might not reflect the reality $[26,27]$.

As a model that contains random coefficients, mixed logit can relax the restrictive independence assumption, then it obviates limitations of standard MNL by capturing the correlations across different ranking levels and allowing for unrestricted substitution patterns [28]. Layton [25] and Calfee et al. [29] reported in their surveys that using randomcoefficient models to analyze ranked preference data could improve the precision of estimation. Another ability of random coefficients is to describe some particular distributions in logit models. Since tourists who arrive at an unfamiliar city are more likely to have limited transport information than traveling in the city they live in, it is of particular concern in this research to explain the role of information in tourists' travel decision-making. The uncertainty of information is more likely to be described as a random distribution rather than a fixed value, and then mixed logit model with random coefficients can help to achieve this goal. Detailed description of random coefficients in this study will be presented in the next sections.

Combining the advantages of ranked logit model and mixed logit model, MRLM can be developed. MRLM not only avoids IIA, but also provides opportunities to build random coefficients as distributions rather than constants. Therefore, this model is especially suitable for this research to describe tourists' perception of uncertainty in information.

2.1. Model Specification. The impacts of ITS are quantified from tourists' ranked choices on transport modes. In every choosing step of the entire ranking under a particular scenario, tourists' perceived utility of each alternative transport mode is assumed to be

$$
U_{n i}=\alpha_{n i} X_{n i}+\omega_{n i}+\varepsilon_{n i} .
$$

In this equation, $U_{n i}$ is the perceived utility of alternative mode $i$ for tourist $n, X_{n i}$ is a vector of parameters (observed attributes of alternative $i$ and observed characteristic of tourist $n$ ), and $\alpha_{n i}$ is a vector of coefficients associated with parameters $X_{n i}$. In this study, some coefficients in $\alpha_{n i}$ are assumed to be random ones. If coefficient $\alpha_{n i}$ is a constant, its probability density function (PDF) can be deemed as $f\left(\alpha_{i}=\right.$ constant $)=1$ across individuals. If coefficient $\alpha_{n i}$ is a random coefficient, $\alpha_{n i}$ is assumed to follow a particular PDF $f\left(\alpha_{i}\right)$ across individuals. The function of $f\left(\alpha_{i}\right)$ commonly needs other parameters $\theta_{i}$ to describe. For example, the PDF of a lognormal distribution $f\left(\alpha_{i}\right)=\exp \left(-\left(\ln \alpha_{i}-\right.\right.$ $\left.\mu)^{2} / 2 \sigma^{2}\right) /\left(\alpha_{i} \sigma \sqrt{2 \pi}\right)$ is decided by two parameters $\mu$ and $\sigma$, then these two parameters are collectively included in $\theta_{i}$. Therefore, the total utility does not depend on the values of $\alpha_{i}$, but the functions of $\theta_{i}$ actually.

$\omega_{n i}$ is an error term to depict the individual-specific unobserved factors of alternative $i$. For each alternative $i$, $\omega_{n i}$ is assumed to be independently and normally distributed across individuals.

With the introduction of random error term $\omega_{n i}$, the restrictive independence assumption in early ranked logit models can be relaxed. Meanwhile, the normal distribution $f\left(\omega_{n i}\right)$ of alternative $i$ and the PDF $f\left(\alpha_{n i}\right)$ are both assumed to be independently and identically distributed (IID) across individuals, that is $f\left(\omega_{i}\right)$ and $f\left(\alpha_{i}\right)$.

$\varepsilon_{n i}$ is an IID extreme-value type one error term across the individuals and the alternatives. This term is assumed to be Gumbel-distributed.

Respondents participating in this research are asked to choose and rank two alternatives in each scenario. If a respondent thinks alternative $i^{(1)}$ is the best one and alternative $i^{(2)}$ is the second-best one from the alternatives set $J$, the conditional probability (conditional on $\alpha_{n i}$ and $\omega_{n i}, i \in J$ ) of the respondent' ranking will be the product of the probability of each choosing step:

$$
\begin{gathered}
P_{n}\left[i^{(1)}, i^{(2)} \mid \alpha_{n i}, \omega_{n i}, i \in J\right] \\
=\frac{\exp \left(\alpha_{n i^{(1)}} X_{n i^{(1)}}+\omega_{n i^{(1)}}\right)}{\sum_{m \in J} \exp \left(\alpha_{n m} X_{n m}+\omega_{n m}\right)} \\
\cdot \frac{\exp \left(\alpha_{n i^{(2)}} X_{n i^{(2)}}+\omega_{\left.n i^{(2)}\right)}\right)}{\sum_{k \in J, k \neq i^{(1)}} \exp \left(\alpha_{n k} X_{n k}+\omega_{n k}\right)} .
\end{gathered}
$$

Finally, the unconditional probability of the ranking $\left[i^{(1)}, i^{(2)}\right]$ is calculated as 
TABLE 1: ITS-related variables in Mixed Ranked Logit Model for different types of tourists.

\begin{tabular}{|c|c|c|c|c|c|c|c|c|c|}
\hline \multirow{2}{*}{$\begin{array}{l}\text { ITS-supported travel } \\
\text { services }\end{array}$} & \multirow{2}{*}{ Variable description } & \multirow{2}{*}{ Variable type } & \multicolumn{3}{|c|}{ Logit model of FIT by PT } & \multicolumn{4}{|c|}{ Logit model of FIT by IV } \\
\hline & & & Bicycling & Bus & Taxi & Bicycling & Bus & Taxi & Car \\
\hline \multirow[b]{2}{*}{ Road traffic condition } & In-vehicle travel time & Continuous & & $X_{1}^{(P)}$ & $X_{1}^{(P)}$ & & $-^{\mathrm{a}}$ & $X_{1}^{(I)}$ & $\overline{X_{1}^{(I)}}$ \\
\hline & $\begin{array}{l}\text { Uncertainty in in-vehicle } \\
\text { travel time }\end{array}$ & Binary & & $X_{2}^{(P)}$ & $X_{2}^{(P)}$ & & $-^{\mathrm{a}}$ & $X_{2}^{(I)}$ & $X_{2}^{(I)}$ \\
\hline \multirow{3}{*}{ Parking management } & Vacant parking space & Binary & & & & & & & $\overline{X_{3}^{(I)}}$ \\
\hline & $\begin{array}{l}\text { Uncertainty in vacant } \\
\text { parking space }\end{array}$ & Binary & & & & & & & $X_{4}^{(I)}$ \\
\hline & Parking fee & Continuous & & & & & & & $X_{5}^{(I)}$ \\
\hline \multirow{8}{*}{$\begin{array}{l}\text { Provision of public } \\
\text { transport and level of } \\
\text { services }\end{array}$} & Vacant public bicycle & Binary & $X_{3}^{(P)}$ & & & $-^{\mathrm{b}}$ & & & \\
\hline & $\begin{array}{l}\text { Uncertainty in vacant } \\
\text { public bicycle }\end{array}$ & Binary & $X_{4}^{(P)}$ & & & $-{ }^{b}$ & & & \\
\hline & Vacant seats on bus & Binary & & $X_{5}^{(P)}$ & & & $X_{6}^{(I)}$ & & \\
\hline & $\begin{array}{l}\text { Uncertainty in vacant seats } \\
\text { on bus }\end{array}$ & Binary & & $X_{6}^{(P)}$ & & & $X_{7}^{(I)}$ & & \\
\hline & Waiting time for bus & Continuous & & $X_{7}^{(P)}$ & & & $X_{8}^{(I)}$ & & \\
\hline & $\begin{array}{l}\text { Uncertainty in waiting time } \\
\text { for bus }\end{array}$ & Binary & & $X_{8}^{(P)}$ & & & $X_{9}^{(I)}$ & & \\
\hline & Waiting time for taxi & Continuous & & & $X_{9}^{(P)}$ & & & & \\
\hline & $\begin{array}{l}\text { Uncertainty in waiting time } \\
\text { for taxi }\end{array}$ & Binary & & & $X_{10}^{(P)}$ & & & & \\
\hline
\end{tabular}

Superscript ${ }^{(P)}$ or ${ }^{(I)}$ denotes that corresponding variable is in the logit model of FIT by PT or the model of FIT by IV, respectively; in the SP surveys for FIT by IV: ${ }^{\mathrm{a}}$ Dedicated bus lanes are in operation; thus the travel time will not change. ${ }^{\mathrm{b}}$ Public bicycles are always available.

$$
\begin{aligned}
P_{n} & {\left[i^{(1)}, i^{(2)}\right] } \\
= & \int_{\omega_{n i}, i \in J} \int_{\alpha_{n i}, i \in J}\left\{P_{n}\left[i^{(1)}, i^{(2)} \mid \alpha_{n i}, \omega_{n i}, i \in J\right]\right\} \\
& \cdot f\left(\alpha_{n i} \mid \theta_{i}\right) d \alpha_{n i} f\left(\omega_{n i}\right) d \omega_{n i} .
\end{aligned}
$$

2.2. ITS-Related Variables in MRLM. Referring to previous studies [7-9], three noteworthy categories of factors are considered as ITS-related variables in MRLM: (1) provision of real-time information, including information about traffic condition, vacant parking space near scenic spots, and waiting time for a bus/taxi, (2) individual vehicle restriction policies, including adjusting parking fee and operating parkand-ride hubs, and (3) quality of public transport services, including in-vehicle environment and travel time. Tourists' perceived uncertainty of certain transport information is considered in corresponding transport modes. Those variables are categorized, designed and described in Table 1 for the logit model of FIT by PT and the logit model of FIT by IV.

The variables regarding "uncertainty" indicate tourists' inaccessibility to particular transport information. The values of these variables are equal to 1 if corresponding information is not available for tourists, otherwise 0 . Therefore, these variables are binary. Consequently, the respondents of the SP surveys can belong to both experimental group and control group under the same hypothetical scenario according to different accessibility to different ITS-supported information.

The design idea of estimating the change due to ITS is explained with example of variables in logit model of FIT by PT. Variable $X_{1}^{(P)}$ denotes the travel time in motorized vehicles, and the values of those variables depend on realtime road condition information released by ITS technology. If information of traffic condition has been released, tourists will take the total decreased utility of $\alpha_{1}^{(P)} X_{1}^{(P)}$ into consideration as the impacts caused by in-vehicle travel time on their modal choices. Under this situation, $X_{2}^{(P)}$ will be correspondingly set as 0 to indicate that uncertainty does not exist in tourists' awareness of traffic condition. Conversely, if tourists do not receive real-time information of traffic condition, the value of $X_{1}^{(P)}$ will be set as 0 , and $X_{2}^{(P)}$ will be set as 1 . The total decreased utilities as the impacts of invehicle travel time then all generate from the lack of realtime information and will be $\alpha_{2}^{(P)} X_{2}^{(P)}$. Since the purpose is to mine tourists' psychological responses when they lack relevant information, it is necessary to set up a reference standard to quantify the impacts. To this end, a covariate $T_{\text {free }}$ is introduced into the calculation of $\alpha_{2}^{(P)}$ by defining $\alpha_{2}^{(P)}=\beta_{2}^{(P)} T_{\text {free }}$, where $T_{\text {free }}$ denotes the travel time in smooth traffic and takes the role of reference standard and $\beta_{2}^{(P)}$ is the associated coefficient of that covariate. By then, the total decreased utility caused by the lack of real-time information is $\beta_{2}^{(P)} T_{\text {free }} X_{2}^{(P)}$. At the same time, tourists are assumed to perceive a length of travel time even though they have no idea about the real traffic condition. This assumption is just like the situation that tourists also receive a released realtime information although it is perceived by themselves, which inspires us to calculate the total decreased utility as the product of tourists' perceived travel time (denoted by $T_{\text {per }}$ ) with coefficient $\alpha_{1}^{(P)}$ (since $\alpha_{1}^{(P)}$ means decreased 
utility caused by every extra minute). In this way, $\alpha_{1}^{(P)} \times$ $T_{\text {per }}=\beta_{2}^{(P)} T_{\text {free }} \times X_{2}^{(P)}$. Because $X_{2}^{(P)}$ equals 1 when realtime information is not provided, $\beta_{2}^{(P)} / \alpha_{1}^{(P)}\left(=T_{\text {per }} / T_{\text {free }}\right)$ will denote the multiple of travel time in smooth traffic perceived by tourists, which is used to reflect tourists' psychological perception.

$X_{3}^{(P)}$ is equal to 1 if a vacant public bicycle remains in the nearest bicycle docking station and the respondent also recognizes that, otherwise, the value is $0 . X_{4}^{(P)}$ concerns the uncertainty of whether a vacant bicycle is available. If the respondent is not accessible to the information of public bicycle system, the value of $X_{4}^{(P)}$ is 1 , otherwise 0 . The values of $X_{5}^{(P)}$ (vacant seats on bus) and $X_{6}^{(P)}$ (uncertainty in vacant seats on bus), $X_{3}^{(I)}$ (vacant parking space) and $X_{4}^{(I)}$. (uncertainty in vacant parking space) are similar to the definitions of $X_{3}^{(P)}$ and $X_{4}^{(P)} \cdot X_{7}^{(P)}$ and $X_{9}^{(P)}$ denote waiting time for bus and taxi, respectively, while $X_{8}^{(P)}$ and $X_{10}^{(P)}$ indicate corresponding uncertainty in waiting time. The method to estimate the perceived waiting time by tourists is similar to the idea dealing with coefficient of $X_{2}^{(P)}$. The only difference is that $X_{8}^{(P)}$ and $X_{10}^{(P)}$ do not contain any covariates. Since $\alpha_{7}^{(P)} \times T_{\text {per_wait }}=\alpha_{8}^{(P)} \times 1$, the value of $\alpha_{8}^{(P)} / \alpha_{7}^{(P)}$ (for bus) or $\alpha_{10}^{(P)} / \alpha_{9}^{(P)}$ (for taxi) indicates the perceived waiting time by tourists.

As for the PDFs of coefficients, coefficients of variables regarding "uncertainty" in waiting time for bus/taxi are assumed to be lognormal distributions so that the signs keep unchanged in the entire domain. This is because waiting time, as well as monetary cost, only causes negative effect in utility. Besides, other coefficients are assumed to be fixed values because hypotheses of random coefficients do not pass the tests.

This study focuses on tourists' transport choices (especially modal shifts of FIT by IV) after they have already arrived in the tourism destination. Without a car, FIT by PT can only rely on local public transport services when traveling. As a result, FIT by PT and FIT by IV will face different set of available transport choices. Moreover, different type of tourists have different sensitivity on different factors. For instance, FIT by IV are mostly sensitive about parking fee and available parking place, while FIT by PT do not take these factors into consideration. Furthermore, if bus service does not have advantages in the travel time when the traffic is congested, FIT by IV can hardly leave from their cars. So in the SP survey for FIT by IV, it is assumed that dedicated bus lanes are in operation and public bicycles are always available so that other factors that may lead to modal shifts can be considered particularly. Therefore, in order to analyze the factors that may be most concerned by different type of tourists, the variables of some transportation mode in each logit model are partially different. It should be pointed out that the set of variables will not influence the generalized application of MRLM. The set of variables in each MRLM depends on its corresponding research objective.
2.3. Mixed Ranked Logit Model in Tourism. From the practical perspective, Mixed Ranked Logit Model that developed in this research also has other advantages in the response analysis among tourists. (1) Various hypothesized scenarios designed in SP surveys help to acquire more data about tourists' response than natural experiments. (2) Cognitive bias in tourists' self-reported perceived waiting time and other feelings can be avoided, since MRLM mines these psychological responses of ITS from tourists' final choices on transport modes. (3) Future possible scenarios can be simulated with MRLM to provide better guidance for the applications of ITS in other tourist cities.

\section{Data Collection}

In order to test the effectiveness of MRLM, SP surveys are conducted in Chengde, a representative tourist city in China. Chengde is approximately $180 \mathrm{~km}$ away from China's capital Beijing. Its UNESCO world cultural heritage site, Mountain Resort and Outlying Temples, attracts a great number of domestic and overseas tourists. With a rapid increasing number of FIT by IV, Chengde is suffering terrible traffic problem these years, especially during peak tourist seasons [30]. To date, Chengde only operates a traditional bus system with about 30 bus lines and real-time transport information system is not available. Aiming to become a smart tourist city, Chengde has launched the plan of Slow Traffic System, which aims to apply ITS technologies to restrict the use of individual vehicles by providing public bicycles and other public transit services for city dwellers and tourists.

To obtain adequate suitable data from real tourists, an on-site questionnaire survey and a subsequent web-based SP survey were carried out within the same sample of tourists who have traveled in Chengde. Respondents stated the attributes of their tourist group during on-site survey and later were classified by their transport modes into two types, namely, FIT by IV and FIT by PT. Different type of tourists would face different scenarios to choose their preferred transport modes in the web-based SP surveys.

3.1. On-Site Questionnaire Survey in Chengde. On-site survey was conducted in Chengde's tourism attractions during China's National Day Holidays (Oct. 1 7) in 2014, when high-density tourist flow occurs within a short period. The respondents are randomly selected. A total of 706 valid onsite questionnaires were collected, including 521 FIT by IV and 185 FIT by PT, which indicates a high proportion of FIT by IV in total FIT, reaching about three-quarters (73.8\%). The surveyed ratio of FIT by IV to FIT by PT is close to the ratio released by Chengde tourism administration.

Table 2 shows a high percentage of FIT by IV who take children $(<10$ years old) or older people ( $>60$ years old) in their journeys, reaching to approximately $60 \%$. In contrast, $87.03 \%$ of FIT by PT groups contain neither children nor older people. The distributions of group size also differ between FIT by IV and FIT by PT. As demonstrated in Figure 1, the group size of FIT by IV is more likely to be 3 to 5 , maybe for the reason that a driving trip is always a family trip and a private car usually have five seats maximum. Lower than FIT 
TABLE 2: Distribution of children and older people in tourist group.

\begin{tabular}{lcc}
\hline Participants in a tourist group & FIT by IV & FIT by PT \\
\hline Presence of children, absence of older people & $24.26 \%$ & $2.16 \%$ \\
Presence of older people, absence of children & $13.73 \%$ & $7.03 \%$ \\
Presence of both children and older people & $20.59 \%$ & $3.78 \%$ \\
Absence of both children and older people & $41.42 \%$ & $87.03 \%$ \\
\hline
\end{tabular}

Child: less than 10 years old; older people: over 60 years old.

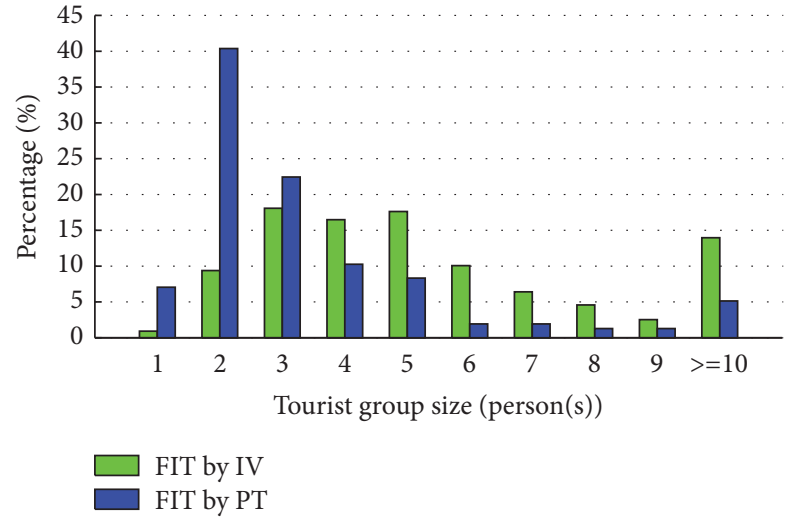

FIGURE 1: Distribution of tourist group size.

by IV, the group size of FIT by PT is more likely to be 2 to 3 . This phenomenon may be explained with the fact that young couples and college students used to travel without personal cars.

3.2. Web-Based Stated Preference Survey. It can be inferred from on-site survey that FIT by IV and FIT by PT may have distinct attitudes and preference. Therefore, in the next step, different versions of SP surveys were designed for different types of tourists. SP surveys were carried out on the web. We asked tourists for their e-mail addresses during the onsite survey and sent the link of the web-based questionnaire via e-mail when they finished their journey. Tourists were encouraged to complete the survey on their mobile phones and tablet PCs by scanning the QR code in the e-mail, since $67.77 \%$ of FITs by IV and $70.65 \%$ of FITs by PT stated in the on-site survey that they would search tourism travel information via smartphones. The process of answering questionnaire on mobile devices is in accordance with their habits in tourism information inquiry. For the same reason, Chengde's tourism ITS plans to distribute information on mobile devices.

Each version of SP survey consists of 48 scenarios with 5 factors, and each factor has 4 levels. As was discussed before, factors were partially different in each version as listed in Table 3. All the scenarios were orthogonally designed with these factors. In an orthogonal experimental design, orthogonality can guarantee that the effect of one factor or interaction can be estimated separately from the effect of any other factor or interaction in the model. By this means, all pairs of factorial levels appear together the same number

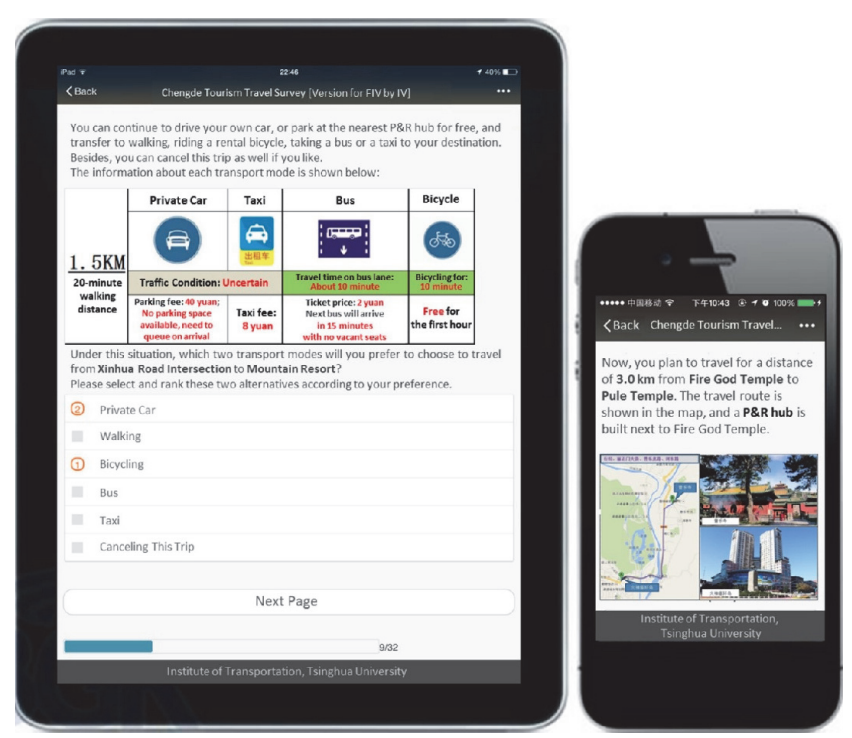

FIgURE 2: Interface of SP survey on tablet PC and mobile phone (translated from Chinese).

of times for each pair of factors, ensuring the coverage of more potential scenario. Consequently, the impacts of each factor can be estimated more efficiently and effectively. An orthogonal experimental design with five 4-level factors could generate 16 scenarios in total. Furthermore, the impacts of travel distance will be considered and three different lengths of travel distance are added to the surveys: $1.5 \mathrm{~km}$, $3 \mathrm{~km}$, and $4.5 \mathrm{~km}$. Since each distance contained 16 scenarios, the total number of scenarios in a survey would be 48 .

Figure 2 shows the interface of the web-based SP survey with examples of hypothesized scenarios. All the transport information was integrated in a card-shaped picture, which implements the suggestion proposed by Kenyon and Lyons [10] so that respondents can soon generate a full and clear image of all the transport modes. In each card-shaped picture, information of a particular transport mode will be described in its corresponding column. Specially, the shading of traffic condition information will be drawn as grey, green, yellow or red when the traffic condition is uncertain (unknown), smooth, slow-moving or congested, respectively. The predicted travel time in each traffic condition is in accordance with Table 4 . The values in this table are set according to real travel experiences along with the calculation of average waiting time in signed road intersections. As urban area in Chengde has always been developing around the Mountain Resort and along the ancient imperial road, most tourism 
TABLE 3: Description of variables and levels in hypothetical scenarios.

\begin{tabular}{|c|c|c|c|c|c|}
\hline Version of SP survey & Factors in surveys & Level 1 & Level 2 & Level 3 & Level 4 \\
\hline \multirow{3}{*}{ For both surveys } & Road traffic condition & Uncertain & Smooth & Slow-moving & Congested \\
\hline & Vacant seats on bus & Uncertain & Enough & Only a few & None left \\
\hline & Waiting time for bus (minute) & Uncertain & 5 & 10 & 15 \\
\hline \multirow{2}{*}{ For FIT by IV } & Vacant parking space & Uncertain & Enough & Only a few & None left \\
\hline & Parking fee (RMB yuan) & 10 & 20 & 30 & 40 \\
\hline \multirow{2}{*}{ For FIT by PT } & Vacant public bicycle & Uncertain & Enough & Only a few & None left \\
\hline & Waiting time for taxi (minute) & Uncertain & 5 & 10 & 15 \\
\hline
\end{tabular}

TABLE 4: Assumed in-vehicle travel time in different traffic condition (minute).

\begin{tabular}{lcccccc}
\hline Road traffic & \multicolumn{2}{c}{$\begin{array}{c}\text { In-vehicle } \\
\text { travel time } \\
(1.5 \mathrm{~km})\end{array}$} & \multicolumn{2}{c}{$\begin{array}{c}\text { In-vehicle } \\
\text { travel time } \\
(3.0 \mathrm{~km})\end{array}$} & \multicolumn{2}{c}{$\begin{array}{c}\text { In-vehicle } \\
\text { travel time } \\
(4.5 \mathrm{~km})\end{array}$} \\
Condition & Bus & Taxi/car & Bus & Taxi/car & Bus & Taxi/car \\
\hline Smooth & 10 & 6 & 14 & 10 & 20 & 13 \\
Slow-moving & 15 & 11 & 24 & 18 & 32 & 25 \\
Congested & 25 & 20 & 38 & 30 & 48 & 40 \\
\hline
\end{tabular}

attractions and other buildings are mixed in the downtown area. Therefore, the roads linking tourism attractions are mostly narrow urban streets and the average velocity is relatively low in Chengde downtown area.

Respondents need imagine that they are still traveling in Chengde with the same group members and choose the best two transport modes under each scenario. In order to simulate the real-world scenes experienced by tourists, all the hypothesized travel routes are designed according to real popular routes in Chengde. Furthermore, to avoid respondents' impatience and ensure the effectiveness of the answers, of the whole 48 scenarios, only 12 will be randomly selected and faced by the respondents.

\section{Estimation Results}

Simulated maximum-likelihood procedure is employed here to estimate the parameters $\theta_{i}$ and then the coefficients $\alpha_{i}$ and $\omega_{i}$. The probabilities in (3) can be approximated through simulation with different realization of $\alpha_{i}$ and $\omega_{i}$ for any given values of $\theta_{i}$ [28]. (1) Draw a value for each $\alpha_{i}$ and $\omega_{i}$ from their PDF $f\left(\alpha_{i} \mid \theta_{i}\right)$ and $f\left(\omega_{i}\right)(i \in J)$, respectively, and mark them as $\alpha_{i}^{r}$ and $\omega_{i}^{r}$ with the superscript $r=1$ to denote the first draw. (2) Use this draw to calculate the ranking probability $P_{n}\left[i^{(1)}, i^{(2)} \mid \alpha_{i}^{r}\left(\theta_{i}\right), \omega_{i}^{r}, i \in J\right]$. (3) Repeat the first and the second steps many times and obtain the average. Then the average is the simulated probability:

$$
\breve{P}_{n}\left[i^{(1)}, i^{(2)}\right]=\frac{1}{R} \sum_{r=1}^{R} P_{n}\left[i^{(1)}, i^{(2)} \mid \alpha_{i}^{r}\left(\theta_{i}\right), \omega_{i}^{r}, i \in J\right] .
$$

In this equation, $R$ is the number of draws of $\omega_{i}$ and $\alpha_{i}$ $(i \in J)$. For each $\omega_{i}$ and $\alpha_{i}$, we use $R=2000$ draws of Halton sequence [31]. Then $\breve{P}_{n}\left[i^{(1)}, i^{(2)}\right]$ is an unbiased estimator of
$P_{n}\left[i^{(1)}, i^{(2)}\right]$ by construction. The simulated probabilities are inserted into the log-likelihood function to give simulated log likelihood, and the estimator is the value of $\theta_{i}$ and $\omega_{i}$ that maximizes this function:

$$
\mathrm{SLL}^{*}=\sum_{n=1}^{N} \sum_{t=1}^{T} \sum_{k=1}^{K} \delta_{k t} \ln \breve{P}_{n}\left[i^{(1)}, i^{(2)}\right],
$$

where $\delta_{k t}=1$ if the best two alternatives are chosen and ranked as $\left[i^{(1)}, i^{(2)}\right]$ under the scenario $t$, and otherwise $\delta_{k t}=$ $0 ; K=A_{J}^{2}$ is the number of all possible permutations of ranking 2 items from $J$ alternatives; $J$ is the number of all the scenarios that respondent $n$ will face in a survey, $T=12$ in both models for FIT by PT and FIT by IV, and $N$ is the number of total respondents in each model.

Tourists may cancel their planned routes if the traffic is terrible. Therefore, "canceling" are added as an alternative as other transport modes. The alternative "canceling" does not include any attributes, and its utility is assumed to be zero (for theoretical and empirical modeling considerations). Consequently, $J$ equals 5 for FIT by PT, that is walking, bicycling, bus, taxi and canceling, and $J$ equals 6 for FIT by IV, that is walking, bicycling, bus, taxi, car and canceling. Of the total 185 FIT by PT and 521 FIT by IV who answered the on-site questionnaires, 121 FIT by PT and 235 FIT by IV completed the web-based SP surveys. Every respondent needs to make decisions in 12 randomly selected scenarios, and every scenario can be seen as a single observation. Therefore the total number of observations in MRLM of FIT by PT and MRLM of FIT by IV will be $1452(=121 \times 12)$ and $2820(=235$ $\times 12$ ), respectively.

All the variables in each MRLM, including ITS-related variables, attribute variables of tourist groups and other public variables (e.g., travel distance) are estimated together. The estimation are calculated with programming language of MATLAB. The results are listed in Table 5.

As discussed in Section 2, the ranking response can provide more preference data than answers of single choice from the same scale of respondents. Therefore, ranked data can improve the precision of estimation with Mixed Ranked Logit Model compared to mixed logit model. Furthermore, based on respondent ranking of alternatives, ranked logit model with fixed coefficients (i.e., standard logit model that restricts $\omega_{n i}$ and $\alpha_{n i}$ in the MRLM to be constants across individuals) is also estimated. The log-likelihood values at convergence in the Mixed Ranked Logit Models are -1538.64 (model for FIT by PT) and -3548.04 (model for FIT by IV), 
TAble 5: Estimated coefficients in Mixed Ranked Logit Model.

\begin{tabular}{|c|c|c|c|c|c|c|c|}
\hline \multirow{3}{*}{ Variables } & \multirow{3}{*}{$\begin{array}{l}\text { Distribution } \\
\text { hypothesis }\end{array}$} & \multicolumn{3}{|c|}{ FIT by PT } & \multicolumn{3}{|c|}{ FIT by IV } \\
\hline & & \multicolumn{2}{|c|}{ Estimated parameter $\theta$} & \multirow{2}{*}{$\begin{array}{l}\text { Estimated } \\
\text { coefficient } \\
\text { (Std. error) }\end{array}$} & \multicolumn{2}{|c|}{ Estimated parameter $\theta$} & \multirow{2}{*}{$\begin{array}{c}\text { Estimated } \\
\text { coefficient } \\
\text { (Std. error) }\end{array}$} \\
\hline & & $\begin{array}{c}\mu \\
\text { (Std. error) }\end{array}$ & $\begin{array}{c}\sigma \\
\text { (Std. error) }\end{array}$ & & $\begin{array}{c}\mu \\
\text { (Std. error) } \\
\end{array}$ & $\begin{array}{c}\sigma \\
\text { (Std. error) } \\
\end{array}$ & \\
\hline In-vehicle travel time & Constant & & & $\begin{array}{l}-0.0514 \\
(0.0058)^{* * *}\end{array}$ & & & $\begin{array}{l}-0.0690 \\
(0.0064)^{* * *}\end{array}$ \\
\hline $\begin{array}{l}\text { Uncertainty in in-vehicle } \\
\text { travel time (covariate } \beta)\end{array}$ & Constant & & & $\begin{array}{l}-0.0765^{\mathrm{a}} \\
(0.0126)^{* * *}\end{array}$ & & & $\begin{array}{l}-0.1671^{\mathrm{a}} \\
(0.0169)^{* * *}\end{array}$ \\
\hline Vacant parking space & Constant & & & & & & $\begin{array}{c}0.2534 \\
(0.1566)\end{array}$ \\
\hline $\begin{array}{l}\text { Uncertainty in vacant } \\
\text { parking space }\end{array}$ & Constant & & & & & & $\begin{array}{c}0.2037 \\
(0.1755)\end{array}$ \\
\hline Parking fee & Constant & & & & & & $\begin{array}{c}-0.0225 \\
(0.0058)^{* * *}\end{array}$ \\
\hline Vacant seats on bus & Constant & & & $\begin{array}{c}0.1171 \\
(0.1228)\end{array}$ & & & $\begin{array}{c}0.5094 \\
(0.1271)^{* * *}\end{array}$ \\
\hline $\begin{array}{l}\text { Uncertainty in vacant } \\
\text { seats on bus }\end{array}$ & Constant & & & $\begin{array}{c}0.0401 \\
(0.1246)\end{array}$ & & & $\begin{array}{c}0.1565 \\
(0.1372)\end{array}$ \\
\hline Vacant bicycles & Constant & & & $\begin{array}{c}0.6075 \\
(0.1212)^{* * *}\end{array}$ & & & \\
\hline $\begin{array}{l}\text { Uncertainty in vacant } \\
\text { bicycles }\end{array}$ & Constant & & & $\begin{array}{l}-0.2957 \\
(0.1425)^{* *}\end{array}$ & & & \\
\hline Waiting time for bus & Constant & & & $\begin{array}{c}-0.0346 \\
(0.0140)^{* *}\end{array}$ & & & $\begin{array}{l}-0.0305 \\
(0.0157)^{*}\end{array}$ \\
\hline Waiting time for taxi & Constant & & & $\begin{array}{l}-0.0364 \\
(0.0179)^{* *}\end{array}$ & & & \\
\hline $\begin{array}{l}\text { Uncertainty in waiting } \\
\text { time for bus }\end{array}$ & Lognormal & $\begin{array}{l}-0.5963 \\
(0.3567)^{*}\end{array}$ & $\begin{array}{c}0.6236 \\
(0.4214)\end{array}$ & $\begin{array}{c}-0.6700^{\mathrm{b}} \\
{[0.4644]}\end{array}$ & $\begin{array}{l}-0.9289 \\
(0.6657)\end{array}$ & $\begin{array}{c}0.7121 \\
(0.5176)\end{array}$ & $\begin{array}{r}-0.5084^{\mathrm{b}} \\
{[0.4157]}\end{array}$ \\
\hline $\begin{array}{l}\text { Uncertainty in waiting } \\
\text { time for taxi }\end{array}$ & Lognormal & $\begin{array}{c}-0.5662 \\
(0.5193) \\
\end{array}$ & $\begin{array}{c}0.7308 \\
(0.3983)^{*} \\
\end{array}$ & $\begin{array}{r}-0.7688^{\mathrm{b}} \\
{[0.6484]} \\
\end{array}$ & & & \\
\hline Walking & Normal & $\begin{array}{c}5.6425 \\
(0.3369)^{* * *}\end{array}$ & $\begin{array}{c}1.7960 \\
(0.1551)^{* * *}\end{array}$ & $\begin{array}{l}5.6425^{\mathrm{c}} \\
{[1.7960]}\end{array}$ & $\begin{array}{c}4.8023 \\
(0.5471)^{* * *}\end{array}$ & $\begin{array}{l}2.2538 \\
(0.2157)^{* * *}\end{array}$ & $\begin{array}{r}.8023^{c} \\
{[2.2538]}\end{array}$ \\
\hline Bicycling & Normal & $\begin{array}{c}3.8593 \\
(0.3684)^{* * *}\end{array}$ & $\begin{array}{c}1.3643 \\
(0.1138)^{* * *}\end{array}$ & $\begin{array}{l}3.8593^{\mathrm{c}} \\
{[1.3643]}\end{array}$ & $\begin{array}{c}3.8529 \\
(0.4123)^{* * *}\end{array}$ & $\begin{array}{c}1.8593 \\
(0.1696)^{* * *}\end{array}$ & $\begin{array}{l}3.8529^{c} \\
{[1.8593]}\end{array}$ \\
\hline Bus & Normal & $\begin{array}{c}5.3887 \\
(0.3925)^{* * *}\end{array}$ & $\begin{array}{c}1.0621 \\
(0.1236)^{* * *}\end{array}$ & $\begin{array}{l}5.3887^{\mathrm{c}} \\
{[1.0621]}\end{array}$ & $\begin{array}{c}3.2231 \\
(0.4064)^{* * *}\end{array}$ & $\begin{array}{c}0.9798 \\
(0.1440)^{* * *}\end{array}$ & $\begin{array}{l}3.2231^{\mathrm{c}} \\
{[0.9798]}\end{array}$ \\
\hline Taxi & Normal & $\begin{array}{c}3.0769 \\
(0.3805)^{* * *}\end{array}$ & $\begin{array}{c}1.5384 \\
(0.1371)^{* * *}\end{array}$ & $\begin{array}{l}3.0769^{c} \\
{[1.5384]}\end{array}$ & $\begin{array}{c}2.9592 \\
(0.4003)^{* * *}\end{array}$ & $\begin{array}{c}1.5093 \\
(0.1227)^{* * *}\end{array}$ & $\begin{array}{l}2.9592^{c} \\
{[1.5093]}\end{array}$ \\
\hline Car & Normal & & & & $\begin{array}{c}4.8422 \\
(0.4809)^{* * *} \\
\end{array}$ & $\begin{array}{c}2.1400 \\
(0.1751)^{* * *}\end{array}$ & $\begin{array}{c}4.8422^{\mathrm{c}} \\
{[2.1400]} \\
\end{array}$ \\
\hline \multicolumn{8}{|c|}{ Estimated coefficients of public variables for each transport mode are shown in Table 7} \\
\hline \multicolumn{2}{|l|}{ Summary statistics } & \multicolumn{3}{|c|}{ MRLM of FIT by PT } & \multicolumn{3}{|c|}{ MRLM of FIT by IV } \\
\hline \multicolumn{2}{|c|}{ Number of observations $(N \times T)$} & \multicolumn{3}{|c|}{1452} & \multicolumn{3}{|c|}{2820} \\
\hline \multicolumn{2}{|l|}{ Likelihood ratio index $\rho$} & \multicolumn{3}{|c|}{0.3565} & \multicolumn{3}{|c|}{0.3118} \\
\hline \multicolumn{2}{|l|}{ SLL at convergence $\operatorname{SLL}(\breve{\theta})$} & \multicolumn{3}{|c|}{-1538.64} & \multicolumn{3}{|c|}{-3548.04} \\
\hline
\end{tabular}

respectively. The corresponding values in the ranked standard logit models are -1487.05 (model for FIT by PT) and -3459.13 (model for FIT by IV), respectively. Then the log-likelihood values clearly indicate that MRLM can fit the response data better than the ranked standard logit models.
In the estimation result of MRLM, the standard deviations of the individual-specific error terms are discovered to be statistically significant, which reveals that individualspecific unobserved factors that influence personal utility for each transportation mode strongly exist. 
TABLE 6: Characteristics of equivalent perceived waiting time.

\begin{tabular}{lccc}
\hline Equivalent perceived waiting time & $\begin{array}{c}\text { Waiting time for bus } \\
\text { (FIT by IV) }\end{array}$ & $\begin{array}{c}\text { Waiting time for bus } \\
\text { (FIT by PT) }\end{array}$ & $\begin{array}{c}\text { Waiting time for taxi } \\
\text { (FIT by PT) }\end{array}$ \\
\hline Mode (most probable value, $e^{\mu-\sigma^{2}}$ ) & $7.80 \mathrm{~min}$ & $10.79 \mathrm{~min}$ & $9.46 \mathrm{~min}$ \\
Mean (average value, $e^{\mu+\sigma^{2} / 2}$ ) & $16.67 \mathrm{~min}$ & $19.36 \mathrm{~min}$ & $21.08 \mathrm{~min}$ \\
\hline
\end{tabular}

Note: equivalent perceived waiting time is lognormally distributed as $\ln N\left(\mu, \sigma^{2}\right)$.

In the following sections, estimation results of ITS-related variables and other variables will be described in detail.

4.1. ITS-Related Variables. The lack of real-time information heightens tourists' perceived risk of longer travel time. Comparing the values between -0.0514 and -0.0765 , $0.0765 / 0.0514=1.49$, which indicates that the impact of lacking traffic condition information is equal to the situation that FIT by PT are told to spend about 1.49 times of travel time that is needed in smooth traffic. As for FIT by IV, their perceived travel time will be $2.42(0.1671 / 0.069)$ times of that. This result maybe a consequence of frequent traffic congestion experienced by FIT by IV. They concern road traffic condition much more than FIT by PT and then overestimate their risk at a higher level.

In terms of the variables relevant with parking management, receiving the information that vacant parking space is available will stimulate the use of private car (0.2534). However, raising the parking fee can significantly reduce the utility of driving a private car, with the coefficient of -0.0225 (per RMB yuan), which provides an evidence to employ economic method to adjust the usage of cars.

Vacant seats on bus, or more comfortable on-bus environment, will attract more FIT by IV to take a bus (0.5094). But in the model of FIT by PT, vacant seats do not affect the utility of bus significantly.

Longer waiting time means less utility for tourists, and the impacts of waiting time on bus and taxi are almost the same $(-0.0346$ and -0.0364 for FIT by PT, resp.). As mentioned above, the coefficients of variables "uncertainty in waiting time for bus/taxi" are assumed to be lognormal distributions. Therefore, two parameters, mean and standard deviation, should be estimated to describe tourists' perceived waiting time which is also lognormal distributed. For FIT by PT, the values of mean of the final estimated coefficients $\alpha$ are -0.67 and -0.7688 for bus and taxi, respectively. If dividing the values of mean by the coefficients of released waiting time, that is -0.0346 and -0.0364 , respectively, the equivalent expected waiting time in average can be calculated. $-0.67 /-0.0346=19.36$, which indicates the average equivalent waiting time for bus is expected to be 19.36 minutes, is higher than the maximum released waiting time in SP survey15 minutes. This phenomenon also occurs in the transport mode of taxi. If tourists do not know the waiting time for taxi, their equivalent perceived waiting time will be average $21.08(-0.7688 /-0.0364)$ minutes. Similarly, we can also calculate equivalent waiting time for bus perceived by FIT by IV in average: $16.67(-0.5084 /-0.0305)$ minutes. The main characteristics of equivalent waiting time for bus and taxi of FIT by PT and FIT by IV are listed in Table 6. "Mode" in this table indicates the most probable equivalent perceived waiting time, while "mean" is the average equivalent perceived waiting time. They are both crucial indices that reflect the impact of uncertainty on the utility of bus and taxi.

The notion "equivalent" used here tries to explain that the impacts of lacking information about waiting time may consist of two parts. One part is the real waiting time while the other part is tourists' perception of the risk. People tend to overestimate the risk under uncertainty; thus the value of information is present in this case: more information can reduce the uncertainty and then ensure the tourists' decisions to be more reasonable.

4.2. Travel Distance and Attributes of Tourist Group. A range of tourists' attributes are tested in model and finds that "gender" and "individual annual income" did not show significant effects on tourists' choice in transport modes. The reason may be that the final decision is more related with attributes of tourist group rather than individual attributes. Table 7 shows the coefficients of public variables for each mode.

The utility of walking will decrease dramatically with the increase in distance, followed by that of bicycling and bus. Generally, the utility of each mode will decrease if a child or an older person exists in a group of FIT by PT, except taxi. This result reveals that taxi will attracts more children and older people for its convenience and safety. As for FIT by IV, they are unwilling to let children or older persons in their tourist group to walk or bicycle, though this effect is not so significant among FIT by PT. The size of tourist group affects the mode choices in a special way. The more persons a tourist group of FIT by PT has, the higher utility of choosing a taxi would be, since it is more worthwhile to share the taxi fare. FITs by IV have shown a similar habit, but larger scale tourist group of them prefer to drive their personal cars and it is uneasy to make a change.

\section{Transport Modal Choice Prediction}

Once each coefficient of Mixed Ranked Logit Model has been estimated, choice probability of transport mode $i$ can be calculated with (6) by applying simulation method:

$$
\breve{P}(i)=\sum_{n} w_{n} \times \frac{1}{R} \sum_{r=1}^{R} \frac{\exp \left(\alpha_{n i}^{r} X_{n i}+\omega_{n i}^{r}\right)}{\sum_{m \in J} \exp \left(\alpha_{n m}^{r} X_{n m}+\omega_{n m}^{r}\right)},
$$

where $w_{n}$ is the percentage of a particular type of tourists $n$.

To fully assess the effect of application of ITS on tourists' transport choices, we predict the changes brought from 
TABLE 7: Estimated coefficients of public variables for each transport mode.

\begin{tabular}{|c|c|c|c|c|c|c|c|c|c|}
\hline \multirow[t]{2}{*}{ Variables } & \multicolumn{4}{|c|}{$\begin{array}{l}\text { Estimated coefficients for FIT by PT } \\
\text { (standard error) }\end{array}$} & \multicolumn{5}{|c|}{$\begin{array}{l}\text { Estimated coefficients for FIT by IV } \\
\text { (standard error) }\end{array}$} \\
\hline & Walking & Bicycling & Bus & Taxi & Walking & Bicycling & Bus & Taxi & Car \\
\hline Distance $(\mathrm{km})$ & $\begin{array}{c}-1.5094 \\
(0.1907)^{* * *}\end{array}$ & $\begin{array}{c}-0.6389 \\
(0.1804)^{* * *}\end{array}$ & $\begin{array}{l}-0.0804 \\
(0.0431)^{*}\end{array}$ & $\begin{array}{l}-0.1575 \\
(0.1853) \\
\end{array}$ & $\begin{array}{c}-1.4618 \\
(0.0933)^{* * *}\end{array}$ & $\begin{array}{c}-0.8038 \\
(0.0613)^{* * *}\end{array}$ & $\begin{array}{c}-0.1441 \\
(0.0497)^{* * *}\end{array}$ & $\begin{array}{l}-0.1161 \\
(0.1911)\end{array}$ & $\begin{array}{l}-0.0821 \\
(0.1783) \\
\end{array}$ \\
\hline $\begin{array}{l}\text { Presence of } \\
\text { children }(<10)\end{array}$ & $\begin{array}{l}-0.3705 \\
(0.2985)\end{array}$ & $\begin{array}{l}-0.3115 \\
(0.2643)\end{array}$ & $\begin{array}{l}-0.4118 \\
(0.3145)\end{array}$ & $\begin{array}{c}0.2604 \\
(0.1653)\end{array}$ & $\begin{array}{l}-0.5578 \\
(0.2303)^{* *}\end{array}$ & $\begin{array}{c}-0.3181 \\
(0.1547)^{* *}\end{array}$ & $\begin{array}{l}-0.2078 \\
(0.1787)\end{array}$ & $\begin{array}{l}-0.1160 \\
(0.1007)\end{array}$ & $\begin{array}{l}-0.1276 \\
(0.2689)\end{array}$ \\
\hline $\begin{array}{l}\text { Presence of } \\
\text { older people } \\
(>60)\end{array}$ & $\begin{array}{c}-0.3489 \\
(0.3171)\end{array}$ & $\begin{array}{l}-0.3791 \\
(0.3217)\end{array}$ & $\begin{array}{l}-0.2874 \\
(0.2195)\end{array}$ & $\begin{array}{c}0.2249 \\
(0.1915)\end{array}$ & $\begin{array}{c}-0.8619 \\
(0.3560)^{* *}\end{array}$ & $\begin{array}{c}-0.4772 \\
(0.2322)^{* *}\end{array}$ & $\begin{array}{l}-0.1502 \\
(0.1289)\end{array}$ & $\begin{array}{l}-0.2191 \\
(0.1903)\end{array}$ & $\begin{array}{l}-0.1213 \\
(0.1747)\end{array}$ \\
\hline \multirow{4}{*}{ Group size $^{\mathrm{a}}$} & \multicolumn{4}{|c|}{ Over 2 persons } & \multicolumn{5}{|c|}{$3 \sim 5$ persons } \\
\hline & $\begin{array}{c}0.3412 \\
(0.5074)\end{array}$ & $\begin{array}{c}0.2891 \\
(0.1980)\end{array}$ & $\begin{array}{c}0.2929 \\
(0.1906)\end{array}$ & $\begin{array}{c}0.5306 \\
(0.3317)\end{array}$ & $\begin{array}{c}0.5378 \\
(0.4039)\end{array}$ & $\begin{array}{c}0.2974 \\
(0.2576)\end{array}$ & $\begin{array}{c}0.8249 \\
(0.4248)^{*}\end{array}$ & $\begin{array}{c}1.0137 \\
(0.4738)^{* *}\end{array}$ & $\begin{array}{c}1.3124 \\
(0.5262)^{* *}\end{array}$ \\
\hline & & & & & \multicolumn{5}{|c|}{ Over 5 persons } \\
\hline & & & & & $\begin{array}{c}0.3267 \\
(0.2466)\end{array}$ & $\begin{array}{c}0.2653 \\
(0.2371) \\
\end{array}$ & $\begin{array}{c}0.4445 \\
(0.3588) \\
\end{array}$ & $\begin{array}{c}1.1042 \\
(0.6367)^{*}\end{array}$ & $\begin{array}{c}1.5204 \\
(0.6999)^{* *}\end{array}$ \\
\hline
\end{tabular}

${ }^{*} p<0.1 ;{ }^{* *} p<0.05 ;{ }^{* * *} p<0.01 ;{ }^{\mathrm{a}} 1 \sim 2$ person(s) is the base category of group size.

ITS-supported information services and dedicated bus lanes separately among FITs by PT, and further investigate these influences on FITs by IV. In the simulated scenarios, all the transport information are assumed to be accessible if ITSsupported tourism information system has been applied, such as waiting time for a bus/taxi (ranging from 0 to 15 minutes in a uniform distribution), whether a rental bicycle is available nearby (the probability a tourist can rent a bicycle is assumed to be $80 \%$ ), road traffic condition, and so forth. Two-thirds of tourists will use these real-time information, just as what the surveys discovered. In addition, the probability of having a seat on bus is set as $80 \%$.

5.1. Transport Modal Choice Prediction for FIT by PT. The prediction results of FIT by PT are illustrated in Figure 3, some changes in transport modal choices occur with the application of ITS-supported information services. Without dedicated bus lanes, the choice probability of bicycling meets a significantly growth after providing multimodal real-time information but the share of bus declines when traffic is congested. In contrast, operation of dedicated bus lanes can keep the ridership of bus at a high level, especially in longer travel distances and under congested traffic condition. Meanwhile, the participant rate of bicycling stays at a more reasonable level within the distance of $3 \mathrm{~km}$. These results indicate that the integration of improved public transport and corresponding public transport information services can lead to a more efficient tourism transport market.

5.2. Transport Modal Choice Prediction for FIT by IV. FITs by IV generally strongly rely on their own private car and can hardly transfer to other alternative transport modes if high-quality public transport service is lacking. Therefore, in the following scenarios, both public bicycle system and bus lanes network are assumed to have entered services. The predicted choice probabilities of FIT by IV are demonstrated in Figure 4. The most significant modal shift appears in the share of bus: when roads are congested, buses that move on the dedicated lanes will attract a considerable portion of FITs by IV.

\section{Conclusions and Discussions}

Previous studies have addressed the support of ITSsupported information for the travel of urban dwellers, however, which primarily focused on daily commutes. To go beyond from these attentions to the ITS technological evolution and fill a research gap for the flourishing leisure and tourism industry, this paper investigates both psychological and behavior responses from tourists to ITS-supported travel services.

It is noted that one technical challenge lies in that the randomicity of the tourists' travel routes has substantial difficulties in recording the behavioral change of a certain tourist before and after using ITS-supported services. This particular constraint requires a distinct research approach than longitudinal observation that is commonly used for analyzing commuters' behaviors. Therefore, this study has developed a MRLM to overcome the hurdle in collecting panel data. With the special design in random coefficients, our MRLM not only obviates independence from irrelevant alternatives, but also successfully estimate the influence of uncertainty in information. In the corresponding SP surveys, tourists' perception of waiting time and other evaluations are mined from their final choices on transport modes rather than self-reported psychological responses, which could improve the reliability of the survey results by avoiding cognitive bias towards the questions among tourists. Moreover, the impact due to a particular type of information can be isolated as respondents can be regarded as experimental group and control group of different tested variables in the same scenario. One first major finding obtained from MRLM reveals that tourists would perceive the risk of traffic congestion and overestimate their waiting time without real-time traffic information. For instance, when accurate information of traffic condition is inaccessible, FITs by PT expect the 

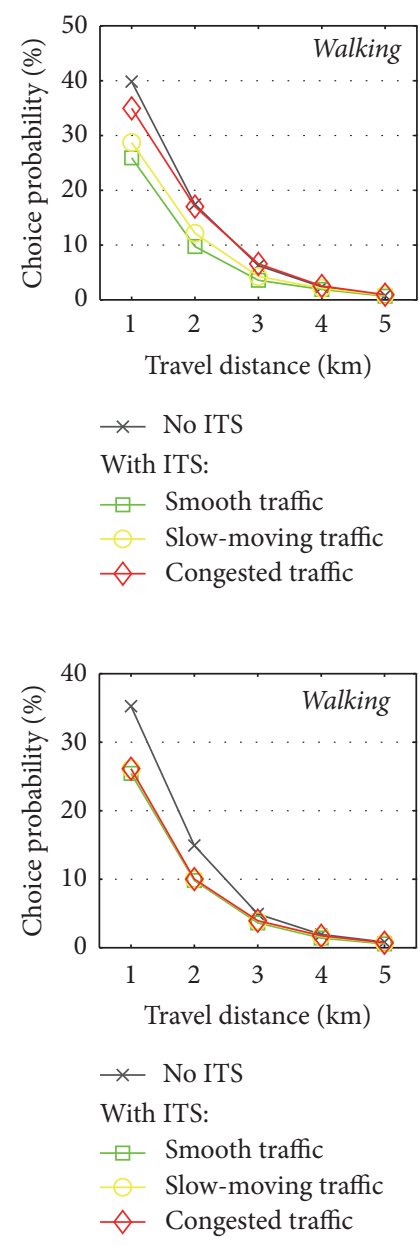
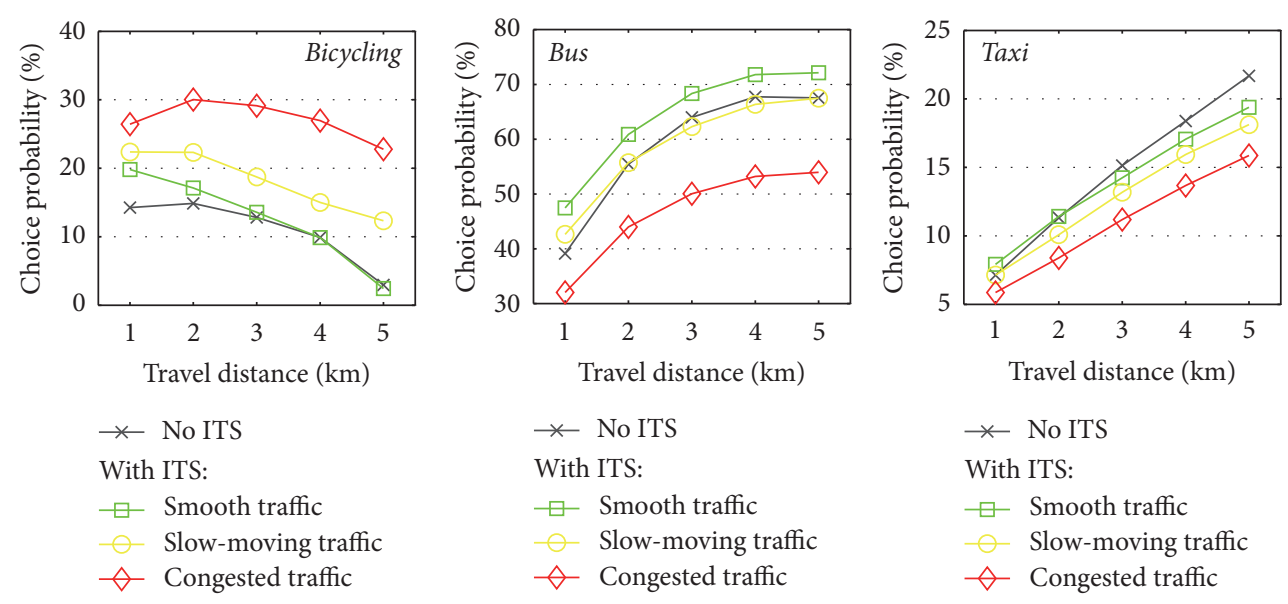

(a) Scenarios: no dedicated bus lanes
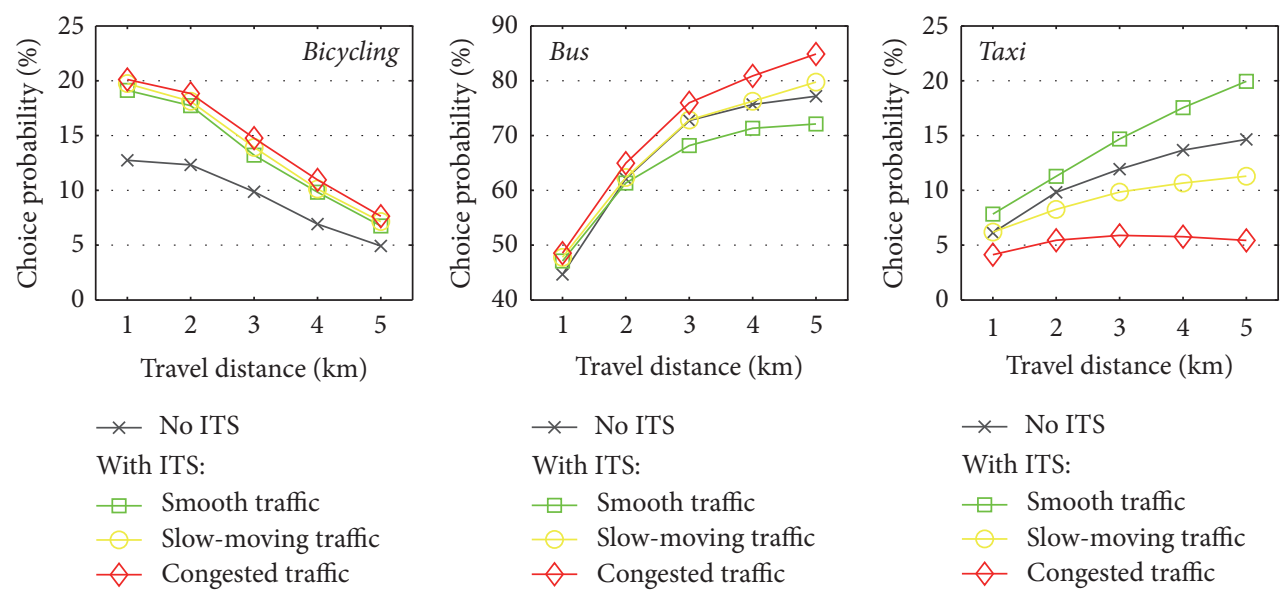

(b) Scenarios: dedicated bus lanes in operation

FIgure 3: Predicted choice probabilities of FIT by PT.

in-vehicle travel time to be 1.49 times of that in smooth traffic, and for FITs by IV the estimate is 2.42 times.

Second, this study also indicates that ITS-supported travel services can encourage modal shifts from individual vehicles to public transit among tourists. Since tourists generally overestimate the out-vehicle waiting time and invehicle travel time, provision of both high-quality public transit services and ITS information are able to reduce tourists' perceived risk caused by information uncertainty. Meanwhile, for FIT by PT, awareness of good in-vehicle environment can increase their willingness to use public transit. These observations also suggest some other improvements (e.g., real-time adjusting departure intervals of buses) can be made for the public transit to attract more FIT by IV in the future. Some characteristics of particular tourist groups also influence the choices in transport modes, which suggests that differentiated market policies should be adopted to promote public transit.

This study focuses tourists' travel mode choices after they have already arrived in tourism destinations. In the SP survey, FIT by PT and FIT by IV would face different transportation alternatives in SP surveys. However, limited by the mathematical characteristics of logit model that is applied in SP surveys, the difference in transportation alternatives and resulting different associated variables of alternatives will cause difficulty in comparing the estimated coefficients of different models. Therefore, the different perceptions towards some travel services between FIT by PT and FIT by IV are hard to be observed. Moreover, responses of travelers without using mobile devices were not collected in this web-based SP survey. This is a limitation caused by survey methodology, because travelers without smartphones may receive some single-modal transport information from other sources (e.g., real-time information board at bus stop). Additional survey is needed if we want to further study the responses of travelers without mobile devices.

Another limitation is the results obtained from SP surveys, as they might not be in line with the reality after actual implementation of ITS, and requires further validation by other practical experiments. One solution is to track actual responses of tourists by launching revealed preference (RP) surveys when planned functions of ITS applications are realized step by step in the future. Meanwhile, a joint $\mathrm{SP} / \mathrm{RP}$ mixed logit model can be developed to reduce the 


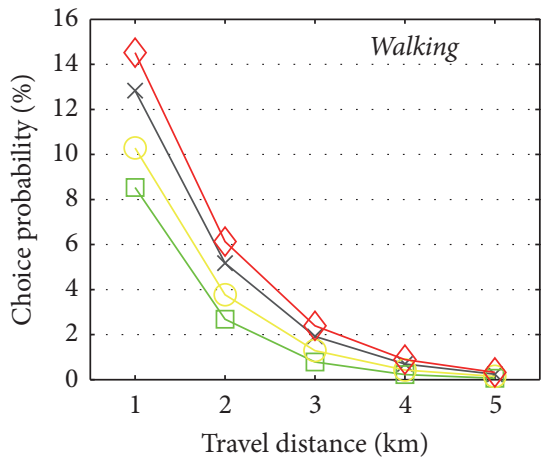

$\rightarrow$ No ITS

With ITS:

$\square$ Smooth traffic

- Slow-moving traffic

$\diamond$ Congested traffic

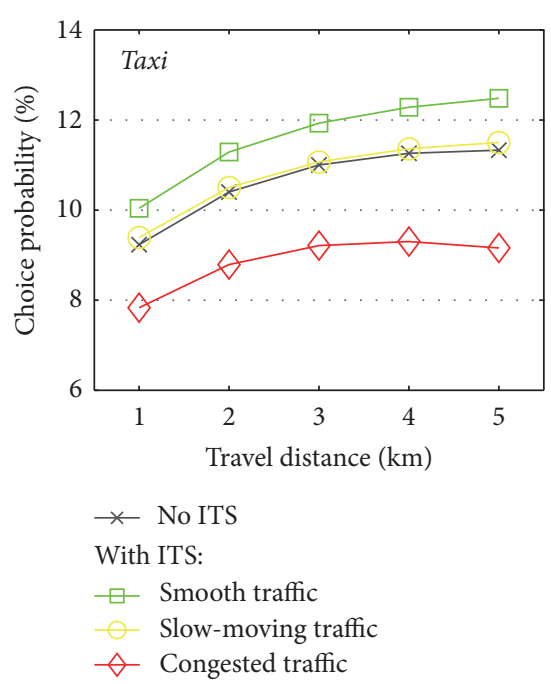

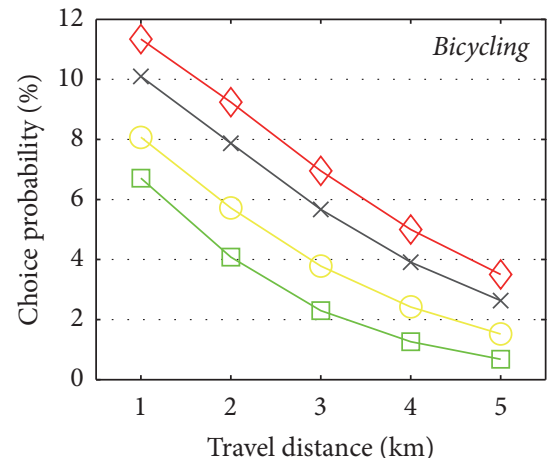

$*$ No ITS

With ITS:

$\square$ Smooth traffic

Slow-moving traffic

$\diamond$ Congested traffic

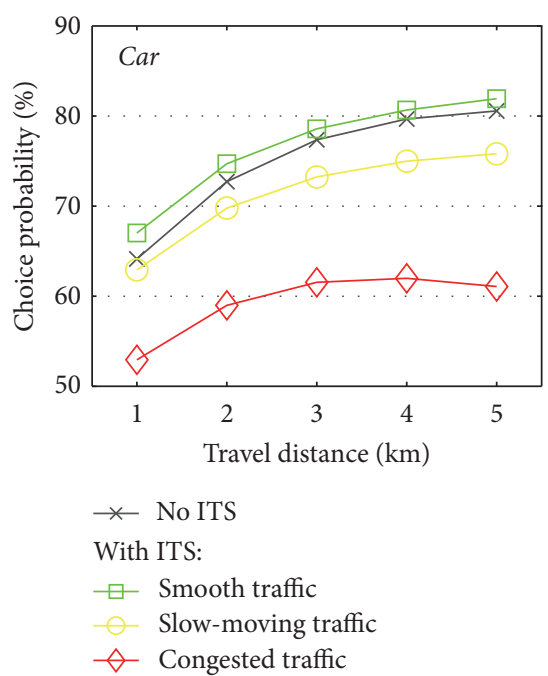

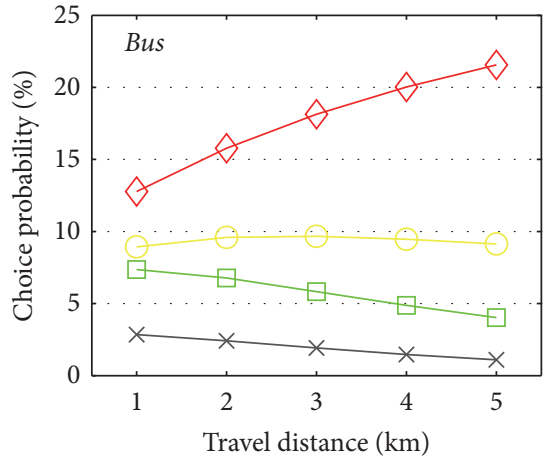

$\rightarrow$ No ITS

With ITS:

$\square$ Smooth traffic

- Slow-moving traffic

$\diamond$ Congested traffic

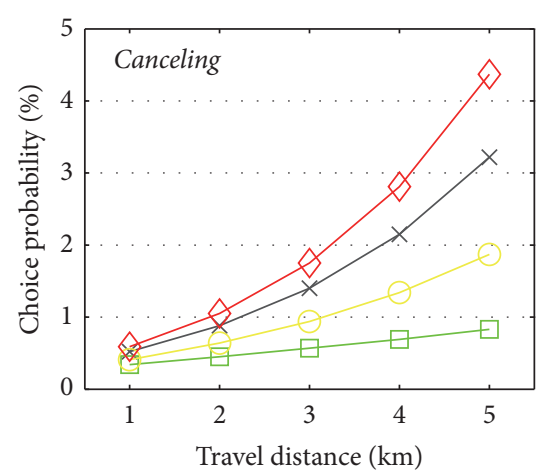

$\rightarrow$ No ITS

With ITS:

$\square$ Smooth traffic

- Slow-moving traffic

$\diamond$ Congested traffic

Figure 4: Predicted choice probabilities of FIT by IV.

potential bias in coefficients estimation and modal choice prediction caused by pure SP data (see, e.g., Hensher et al. [32]). Besides, when simulating the process of releasing transportation information in this research, each hypothetical scenario only contains a single route. While in fact, tourists' travel behavior may be associated with their entire activity chains [33]. This limitation remains to be addressed in future work. Notwithstanding, our study can lead better insights into visitors' potential respondents to ITS-supported travel services in a tourist city, and proposals a novel methodology to assess the impacts of ITS on tourists and their tourism destinations.

\section{Competing Interests}

The authors declare that there is no conflict of interests regarding the publication of this paper.

\section{Acknowledgments}

The authors would like to appreciate the financial support from TOSHIBA Corporation and the National Natural
Science Foundation of China (no. 51578319). They also extend their appreciation to Chengde Travel \& Tourism Administration and Chengde Municipal Institute of City Planning \& Design for the assistance in their surveys. They thank two anonymous referees for their valuable comments on the improvement of this paper.

\section{References}

[1] H. D. Regnerus, R. Beunen, and C. F. Jaarsma, "Recreational traffic management: the relations between research and implementation," Transport Policy, vol. 14, no. 3, pp. 258-267, 2007.

[2] J. Guiver, L. Lumsdon, and R. Weston, "Traffic reduction at visitor attractions: the case of Hadrian's Wall," Journal of Transport Geography, vol. 16, no. 2, pp. 142-150, 2008.

[3] V. Filimonau, "Carbon management in tourism: mitigating the impacts on climate change," Tourism Management, vol. 46, pp. 62-63, 2015.

[4] Tourism Research Center of Chinese Academy of Social Sciences, China's Self-Driving Tourism Development Analysis and Forecast (2015-2016), China Travel \& Tourism Press, Beijing, China, 2016. 
[5] China National Tourism Administration, "Report on China's Tourism Development," 2016 http://www.cnta.gov.cn/xxfb/ hydt/201605/t20160516_770884.shtml.

[6] F. Liu, Research on the development of public transportation of tourism in Changchun based on tourists' experience [M.S. thesis], Northeast Normal University, Changchun, China, 2014.

[7] W. Gronau and A. Kagermeier, "Key factors for successful leisure and tourism public transport provision," Journal of Transport Geography, vol. 15, no. 2, pp. 127-135, 2007.

[8] M. Frima, B. Edvardsson, and T. Gaerling, "Perceived service quality attributes in public transport: inferences from complaints and negative critical incidents," Journal of Public Transportation, vol. 2, no. 1, pp. 67-89, 1998.

[9] M. Schiefelbusch, A. Jain, T. Schäfer, and D. Müller, “Transport and tourism: roadmap to integrated planning developing and assessing integrated travel chains," Journal of Transport Geography, vol. 15, no. 2, pp. 94-103, 2007.

[10] S. Kenyon and G. Lyons, "The value of integrated multimodal traveller information and its potential contribution to modal change," Transportation Research Part F: Traffic Psychology and Behaviour, vol. 6, no. 1, pp. 1-21, 2003.

[11] N. Gammer, T. Cherrett, and C. Gutteridge, "Disseminating real-time bus arrival information via QR code tagged bus stops: a case study of user take-up and reaction in Southampton, UK," Journal of Transport Geography, vol. 34, pp. 254-261, 2014.

[12] R. Mishalani, M. McCord, and J. Wirtz, "Passenger wait time perceptions at bus stops: empirical results and impact on evaluating real-time bus arrival information," Journal of Public Transportation, vol. 9, no. 2, pp. 89-106, 2006.

[13] K. Dziekan and K. Kottenhoff, "Dynamic at-stop real-time information displays for public transport: effects on customers," Transportation Research Part A: Policy and Practice, vol. 41, no. 6, pp. 489-501, 2007.

[14] K. E. Watkins, B. Ferris, A. Borning, G. S. Rutherford, and D. Layton, "Where is my bus? Impact of mobile real-time information on the perceived and actual wait time of transit riders," Transportation Research Part A: Policy and Practice, vol. 45, no. 8, pp. 839-848, 2011.

[15] C. Brakewood, G. S. Macfarlane, and K. Watkins, "The impact of real-time information on bus ridership in New York City," Transportation Research Part C: Emerging Technologies, vol. 53, pp. 59-75, 2015.

[16] F. Zhang, Q. Shen, and K. J. Clifton, "Examination of traveler responses to real-time information about bus arrivals using panel data," Transportation Research Record, no. 2082, pp. 107115, 2008.

[17] B. Ferris, K. Watkins, and A. Borning, "OneBusAway: results from providing real-time arrival information for public transit," in Proceedings of the 28th Annual CHI Conference on Human Factors in Computing Systems (CHI '10), pp. 1807-1816, Atlanta, Ga, USA, April 2010.

[18] A. Gooze, K. Watkins, and A. Borning, "Benefits of real-time transit information and impacts of data accuracy on rider experience," Transportation Research Record, no. 2351, pp. 95103, 2013.

[19] L. Tang and P. V. Thakuriah, "Ridership effects of real-time bus information system: a case study in the city of Chicago," Transportation Research Part C: Emerging Technologies, vol. 22, pp. 146-161, 2012.

[20] C. Brakewood, S. Barbeau, and K. Watkins, "An experiment evaluating the impacts of real-time transit information on bus riders in Tampa, Florida," Transportation Research Part A: Policy and Practice, vol. 69, pp. 409-422, 2014.

[21] D. A. Hensher, "Stated preference analysis of travel choices: the state of practice," Transportation, vol. 21, no. 2, pp. 107-133, 1994.

[22] S. Beggs, S. Cardell, and J. Hausman, "Assessing the potential demand for electric cars," Journal of Econometrics, vol. 17, no. 1, pp. 1-19, 1981.

[23] R. G. Chapman and R. Staelin, "Exploiting rank ordered choice set data within the stochastic utility model," Journal of Marketing Research, vol. 19, no. 3, pp. 288-301, 1982.

[24] J. A. Hausman and P. A. Ruud, "Specifying and testing econometric models for rank-ordered data," Journal of Econometrics, vol. 34, no. 1-2, pp. 83-104, 1987.

[25] D. F. Layton, "Random coefficient models for stated preference surveys," Journal of Environmental Economics and Management, vol. 40, no. 1, pp. 21-36, 2000.

[26] M. Ben-Akiva, T. Morikawa, and F. Shiroishi, "Analysis of the reliability of preference ranking data," Journal of Business Research, vol. 24, no. 2, pp. 149-164, 1992.

[27] K. Sælensminde, "Inconsistent choices in stated choice data; use of the logit scaling approach to handle resulting variance increases," Transportation, vol. 28, no. 3, pp. 269-296, 2001.

[28] K. E. Train, Discrete Choice Methods with Simulation, Cambridge University Press, London, UK, 2nd edition, 2009.

[29] J. Calfee, C. Winston, and R. Stempski, "Econometric issues in estimating consumer preferences from stated preference data: a case study of the value of automobile travel time," Review of Economics and Statistics, vol. 83, no. 4, pp. 699-707, 2001.

[30] Chengde Travel \& Tourism Administration, Chengde's Tourism is Entering the Era of Free Independent Tourists, 2013, http:// www.cdtour.gov.cn/zhijian/cdlyzjw/xydt/363.html.

[31] C. R. Bhat, "Quasi-random maximum simulated likelihood estimation of the mixed multinomial logit model," Transportation Research Part B: Methodological, vol. 35, no. 7, pp. 677-693, 2001.

[32] D. A. Hensher, J. M. Rose, and W. H. Greene, "Combining RP and SP data: biases in using the nested logit "trick" - contrasts with flexible mixed logit incorporating panel and scale effects," Journal of Transport Geography, vol. 16, no. 2, pp. 126-133, 2008.

[33] A. Lew and B. McKercher, "Modeling tourist movements: a local destination analysis," Annals of Tourism Research, vol. 33, no. 2, pp. 403-423, 2006. 


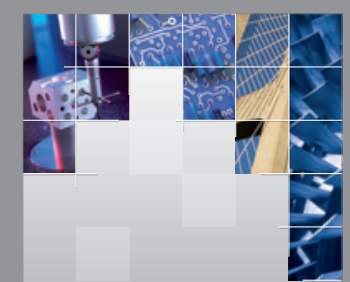

\section{Enfincering}
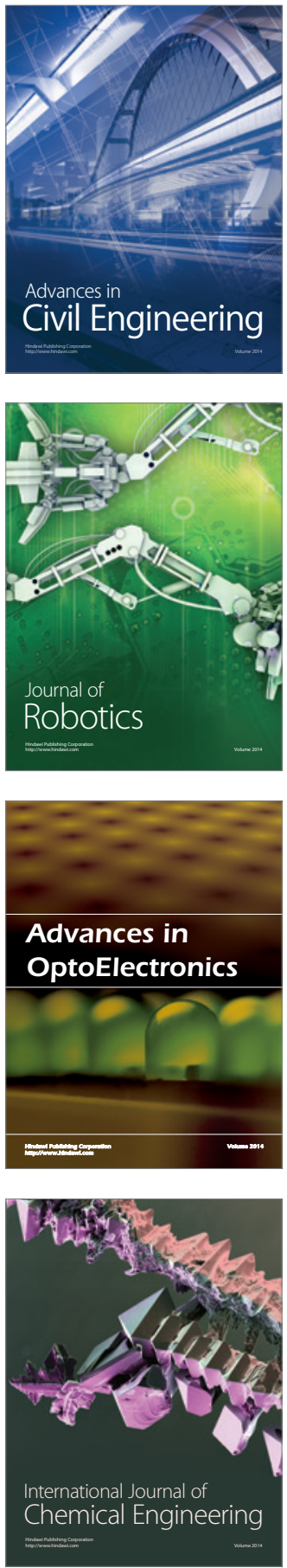

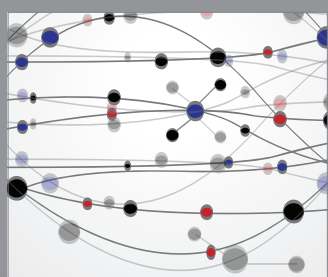

The Scientific World Journal

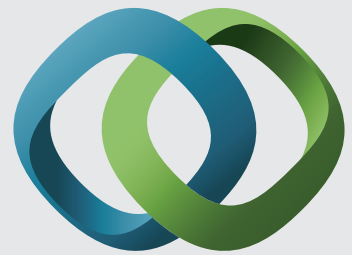

\section{Hindawi}

Submit your manuscripts at

https://www.hindawi.com
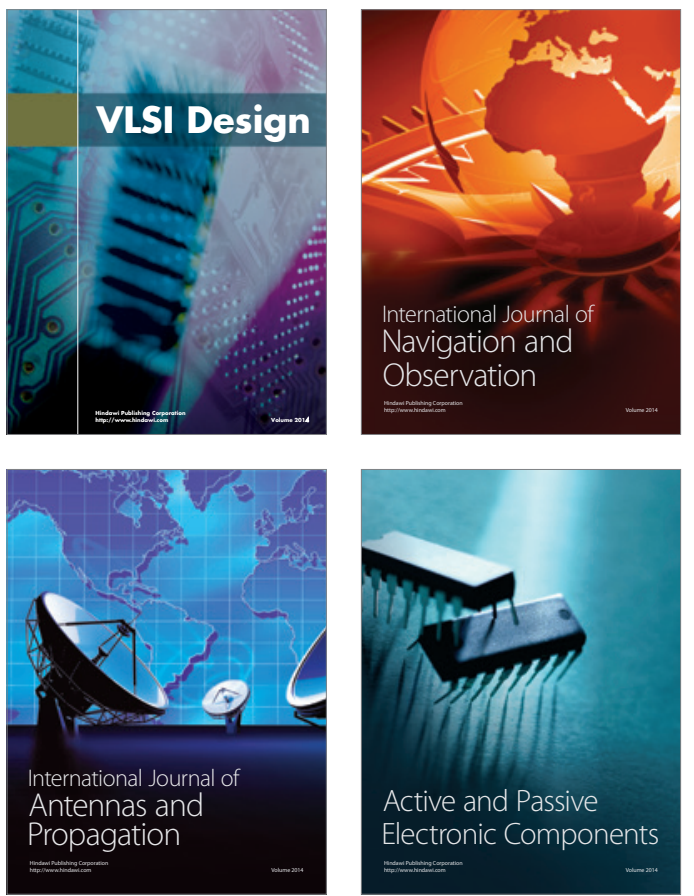
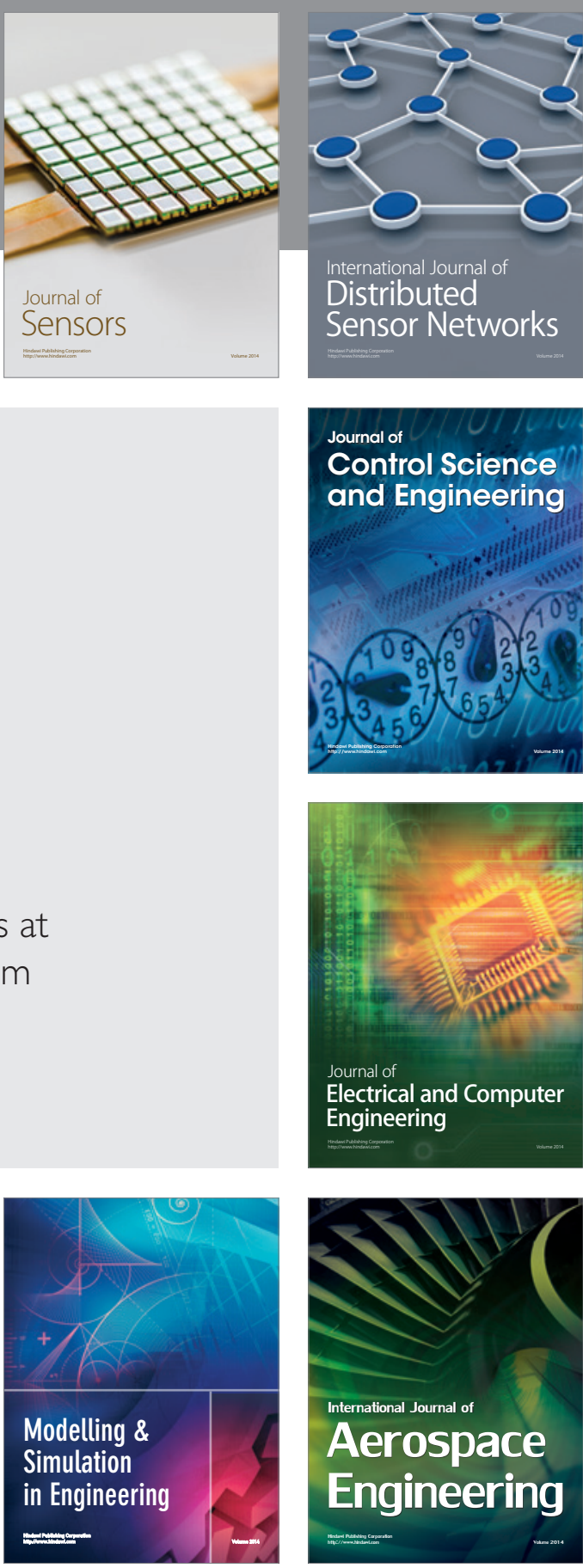

International Journal of

Distributed

Sensor Networks

$-$

Joumal of

Control Science

and Engineering
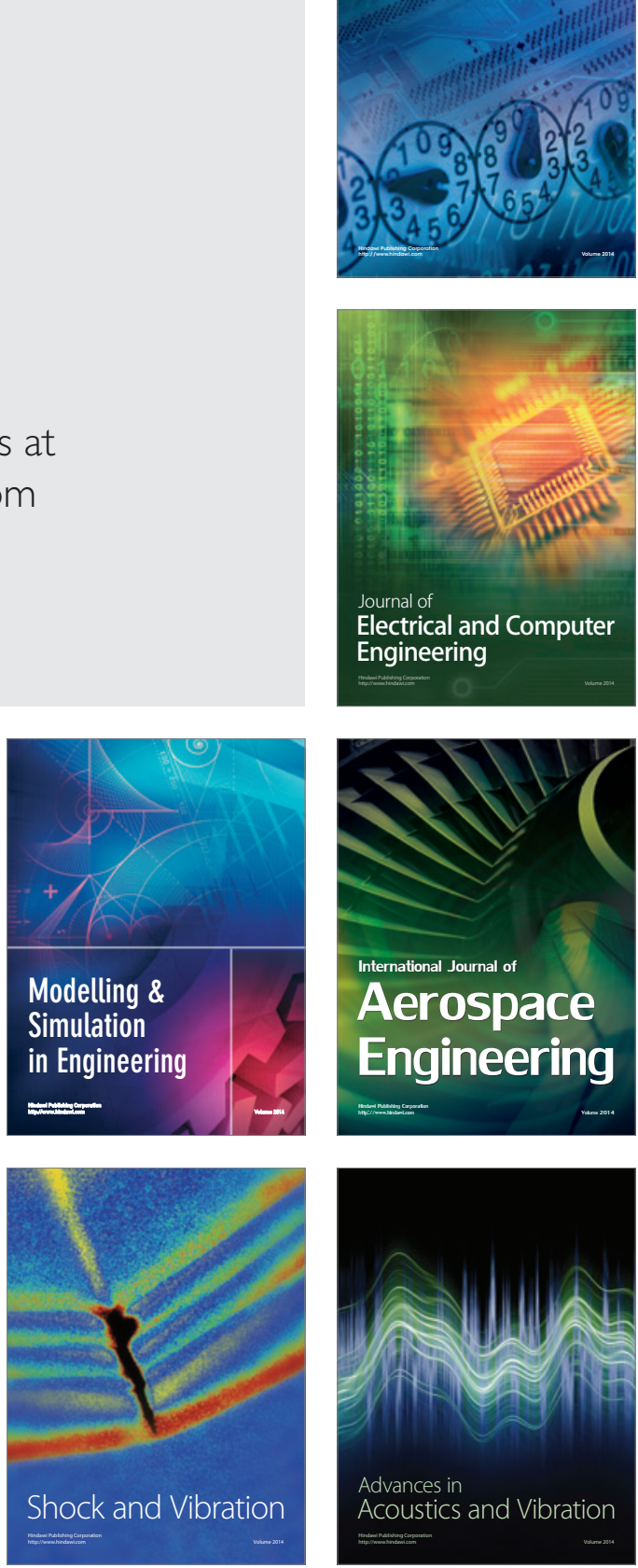